\title{
Clinical Stage I Esophageal Squamous Cell Carcinoma AJCC v8
}

National Cancer Institute

\section{Source}

National Cancer Institute. Clinical Stage I Esophageal Squamous Cell Carcinoma A/CC v8. NCI Thesaurus. Code C133448.

Stage I includes: T1, N0-1, M0. T1: Tumor invades the lamina propria, muscularis mucosae, or submucosa. N0: No regional lymph node metastasis. N1: Tumor with metastasis in one or two regional lymph nodes. M0: No distant metastasis. (AJCC 8th ed.) 